\title{
Managing Telework Programs Effectively
}

\author{
Jeffrey A. Mello
}

Published online: 3 October 2007

(C) Springer Science + Business Media, LLC 2007

\begin{abstract}
Telework has greatly increased in both popularity and use in recent years. The original impetus behind telework has shifted over the years away from social responsibility as employers have come to realize the significant benefits they can reap from a welldesigned and implemented telework program. Despite the well-documented environmental, societal, employer and employee benefits associated with telework, telework changes the nature of the employer-employee relationship and can have some detrimental effects on an organizations if not implemented strategically. This paper explores the prevalence of and benefits and limitations associated with telework and provides recommendations as to how to most effectively implement telework.
\end{abstract}

Key words telework - employers · employee t technology

\section{Introduction}

Initially, the practice of telework was called telecommuting. Telecommuting arrangements traditionally involved an agreement by which the employee worked from her or his residence, using telecommunication links to gain access to the office virtually. The term "telecommute" implied that an employee's "travel" to work was via such telecommunication links. Today, the term "telework" is used more often to refer to employees who work away from the employer's offices in any capacity and includes not only individuals who work from their own home but those who may work at other remote locations such as libraries, internet cafes, hotel rooms, client offices and even on trains and in automobiles.

\footnotetext{
J. A. Mello (凶)

Andreas School of Business, Barry University, 11300 Northeast Second Avenue, Miami Shores, FL 33161-6695, USA

e-mail: jmello@mail.barry.edu
} 
Telework doesn't necessarily mean that employees work at home or in public spaces. Many employers now offer satellite, shared "telework" centers located in or near suburban residential areas. Such work sites are becoming increasingly popular and are equipped with a variety of telecommunications equipment and services as well as work stations/desks/ offices that are shared by employees of a single employer or multiple employers. Telework centers help to overcome some of the problems associated with working at home, such as distractions and safety, while still providing some of the benefits of telework, such as reduced commuting time and operating expenses. Such arrangements are often more palatable to managers who may resist having their subordinates work "at home" for fear that at-home distractions may impact productivity or time committed to actual work (United States Bureau of Transportation Services 2006).

Advances in technology, particularly those related to information processing and telecommunications technology have greatly expanded the availability of telework to employees. Recent technological innovations that have helped fuel telework include the increasing portability of both computers and data files, fax and electronic mail transmission capabilities, the ability to engage in interactive online "chat" sessions with co-workers and/ or customers, video capabilities that allow real time virtual meetings without physical presence of all participants in one room and the networking of computer systems and data lines. The ability of such technological advances to simulate or replicate actual working conditions and patterns of interaction and communication virtually has helped to erode some of the resistance that many mangers and employers have traditionally displayed toward telework.

\section{Popularity}

The increase in the popularity of telework arrangements has paralleled several social and workplace trends, including the movement to a service and information-based economy, the demands by employees for both greater worker flexibility and employee participation in important work-related decisions and employee frustration with lengthening and increasingly costly commutes. This increase in popularity is reflected in the fact that as much as $30 \%$ of the US labor force now works at home at least part of the week (United States Bureau of Transportation Services 2006).

Estimates by the U.S. Dept of Transportation indicate that the number of teleworkers increased by approximately 100\% over the 5-year periods from 1992 to 1997 and then again from 1997 to 2002 (United States Bureau of Transportation Services 2006). The percentage of teleworkers who physically work at home declined during this period from 99 to $50 \%$ of the total while the percentage who work out of telework centers increased from 1 to $50 \%$ (United States Bureau of Transportation Services 2006). Simultaneous to this dynamic, the average number of days per week that the typical employee engaged in telework increased from 1.5 to 3.5 during this 10-year period (United States Bureau of Transportation Services 2006). Currently, 22.2 million Americans, or $16.5 \%$ of the workforce work from home at least 1 day each week (Arnold 2006). Estimates are that by 2010 there will be 20 million employees engaged in telework in the United States (Kirk and Belovics 2006). The benefits of telework have been acknowledged by Congress as reflected in the fact that telework programs are required by law of all federal government agencies. In 2004 19\% of federal government employees engaged in telework at least 1 day each week (Arnold 2006). 
The interest in telework programs transcends national boundaries. National governments in the European Union are promoting telework as a means of reducing traffic congestion as well as a means of expanding the labor pool available to employers (Perez and Sanchez 2005). British labor market analysts and policymakers have taken a keen interest in telework options, noting that they extend and broaden opportunities for individuals to participate in and remain employed (Ruiz and Walling 2005). In the spring of 2005, more than 3 million employees in Britain, or $8 \%$ of the British workforce, engaged in telework (Ruiz and Walling 2005). In Britain, telework transcends gender and gender stereotypes. While many associate telework with female employees who often bear primary responsibilities for family care and household responsibilities, two thirds of teleworkers in Britain are male (Ruiz and Walling 2005).

While Britain has taken a lead among EU nations in promoting telework, other EU member nations have been slower to embrace the practice. This is in spite of the fact that a 1994 report to the European Commission strongly advocated telework as a vital means of contributing to economic growth. (Bangemann 1994). The major reasons for this lack of telework programs have been the resistance of trade unions, the inflexibility of the traditional monolithic corporations that dominate the economies of France, Germany, Italy and Spain, and the relatively low penetration of technology into many areas of Spain, Italy and France (Stallion Technologies 2002).

In Australia, 2.8 million Australians were engaged in telework at the end of 2004. This number is expected to increase to 3.4 million by the beginning of 2008 (Vidal 2004). Telework among Australians is also becoming increasing network-centered rather than isolated. Initial interest in telework was based on the employee benefit dimension, however, more recent interest in telework has been driven by environmental and traffic concerns (Vidal 2004). Productivity among Australians engaged in telework averages $20 \%$ more than their productivity in the office (Garner and Dick 2007).

While the concept of telework holds great interest to both employers and employees, frequently both groups fail to understand and appreciate the full ramifications of what telework involves. Telework involves far more than an agreement, either formal or informal, that an employee can "work at home." Telework impacts the design of work system, team dynamics and organizational culture. As a result, telework programs require a shift in management practices and philosophies about work, supervision, control and autonomy. Supervisors need to feel comfortable allowing subordinates to have more discretion in how they complete work assignments and projects and feel comfortable with delegation and decentralization of the work unit's overall responsibility. Vertical and horizontal work relationships need to be re-examined to ensure that individual departments continue to function both efficiently and effectively as well as maintain productive working relationships with other departments as well as with external constituents.

\section{The Benefits of Telework}

Early telework initiatives in the United States were rooted in social policy issues, focused on the beneficial impact that telework would have on the environment and traffic in urban areas (Arnold 2006). Throughout the European Union, national governments are actively promoting telework as a means of reducing traffic congestion as well as a means of expanding employment opportunities to those who might be unable to physically travel to an employer's place of business. 


\section{Environmental Benefits}

Public policy initiatives that promoted telework were initially conceived and designed to reduce traffic and resultant levels of pollution by alleviating the number of vehicles on the road as telework affords opportunities to secure significant social benefits by reducing the environmental impact of automobile traffic (Harpaz 2002). Telework was also promoted secondarily as a means of alleviating the strain being placed on many public transport systems (Harpaz 2002).

The arguments used to promote telework were based on the fact that telework has a positive effect on air quality and traffic congestion relief as rush-hour/peak commuting hours are a major source of air pollutants. Additionally, fewer automobiles on the road would likely result in fewer highway accidents. One documented environmental effect of telework in the United States is the reduction of up to 35 billion vehicle miles traveled per year with a resultant decline in gasoline consumption of up to 1.7 billion gallons of fuel (United States Bureau of Transportation Services 2006). Estimates have been made concerned the full advantages that the United States economy could realize if telework options were fully implemented. If all employees who could currently engage in telework took full advantage of this option, the reduced driving miles would save the US economy $\$ 3.9$ billion a year in fuel costs and the cumulative time savings would be equal to 470,000 full-time jobs (Rockridge Associates 2006).

One group of 13 diverse Atlanta employers provides free consulting services and financial assistance to other employers considering telework programs. This group, the Telework Leadership Initiative, is part of The Clean Air Campaign, an Atlanta nonprofit, which works with local employers, governments and schools to help reduce traffic congestion and improve air quality. As part of Telework Leadership Initiative, the Clean Air Campaign provides participating employers with up to $\$ 10,000$ in consulting services and up to $\$ 10,000$ in reimbursements for staff time spent developing and implementing telework programs (Bednarz 2005). As of July 2005, the initiative had spawned 1,800 new teleworkers in the Atlanta metro area (Bednarz 2005). CAC studies found that the average of $107 \mathrm{~min}$ that the typical worker spent commuting each day went directly back to the employer in the form of additional work time (Bednarz 2005). This fact helps to dispel the myth that only employees benefit from telework arrangements. Employers reported significant bottom line benefits reaped through increased productivity, improved morale and decreased real estate costs (Bednarz 2005).

\section{Societal Benefits}

While a good deal of the public benefits of telework have focused on the environment, more recent attention has been paid to the employment and social policy benefits of telework. Since the passage of the Americans with Disabilities Act, employers have become much more keenly aware of the rights of employees and job applicants with disabilities as well as the challenges individuals with disabilities face and prejudices they suffer when seeking employment. Because many individuals with disabilities are physically unable to get work, despite being fully qualified to hold a myriad of jobs, telework options can allow employers to more fully utilize the skills and abilities of such individuals. This is true not only for individuals with disabilities who may have limited physical mobility but also for others who may be constrained for other reasons, such as the elderly or new parents who need or prefer to be at home with a child. 
Telework can also provide "reasonable accommodation" to employees and job applicants with disabilities, as mandated by the Americans With Disabilities Act (Arnold 2006). This is particularly true in instances where it is not necessarily an essential job requirement that work be performed in the office. If telework is offered to an employee or job applicant as such reasonable accommodation, the employer may also be required to provide the employee with appropriate technology and office furniture, such as a desk and ergonomic chair. The Supreme Court has ruled that the reasonableness of an accommodation under the ADA, in part, depends upon its cost relative to the size of the organization, its budget and revenues. The critical point here is that any telework policy needs to consider the "essential" functions of jobs and whether it is "essential" for employees to be on-site relative to ADA accommodation.

\section{Employer Benefits}

As employers were initially motivated to offer telework programs altruistically by being persuaded of the environmental, societal and political benefits that telework programs can provide, more recent initiatives have focused on the organization's bottom line. Interest in telework, at this point in time, is largely fueled by reported productivity gains and enhanced overall quality of life for employees. Employers have been able to reap productivity gains and lower operating costs while, at the same time, being afforded an additional tool for recruiting and retaining employees.

The first benefit that employers have realized from telework is increased productivity. This has been realized through teleworkers having fewer distractions than they normally have in the office combined with their willingness to work longer hours. In most cases the time that employees normally spend in traffic and/or commuting to the office is returned to the employer in the form of additional work hours. While estimates do vary, studies have found that the average productivity gains of employees who engage in telework are $10-40 \%$ over that which they experience in an office environment (Nie 1999).

A second documented employer benefit of telework is improved morale and motivation of employees (Kurland and Bailey 1999). Telework arrangements involve a display of trust and confidence in employees. Because there is no direct supervision of employees, telework also encourages independence and autonomy, which is highly valued by many employees. One study found that employees of employers with telework programs perceive greater psychological job control, resulting in significantly lower turnover intentions, family-work conflict and depression (Kossek et al. 2006).

A third employer benefit of telework is that it can provide enhanced customer and client service. Telework options often include a flexibility component which allows employees to choose working hours that are more suited to their lifestyles and body clocks. Telework options, particularly in positions related to customer service, allow employers to transcend geographic and time clock boundaries in their operations, extending the typical 8-h workday to a 24-h one, providing continuous, around-the-clock customer service. More so, telework allows flexibility in the creation of virtual teams that can be established to allow optimal skill utilization and balance with teams that again transcend geography and time zones.

Perhaps the main benefit that has influenced employers to implement telework programs is the documented reduced operating costs offered by telework programs. Telework programs often result in cost savings relative to office rent and occupancy needs, real estate taxes and property maintenance expenses. Cost savings that be incurred from consolidation of space can be significant. Sun Microsystems saved \$69 million in real estate costs in 2005 
through its telework program (Arnold 2006). AT\&T reported that it has saved \$25 million annual since it formally implemented a telework program in 1992 Arnold 2006).

Honolulu-based Outrigger Hotels and Resorts has implemented a system that allows all of its 55 call center employees to work from home. The expected cost savings are 35\% annually and additional cost savings will be incurred as the company expects to lower its turnover rate as a result of its program. This follows a trend that other employers have embraced. In 2005, there were more than 110,000 home-based customer service employees working for call center services with the projection that that number will increased by $20 \%$ annually (Thibodeau 2006).

Further cost savings can be realized through telework programs. Telework programs that allow individuals to remain employed when they need to relocate for personal/family reasons can reduce costs related to turnover and recruiting replacements. Telework programs that expand an employer's applicant pool beyond a reasonable commuting distance can allow employers to hire the best applicant who otherwise might not be available without having to offer and assume relocation expenses for such an individual.

A fifth benefit of telework programs is that they have been shown to reduce employee absenteeism and turnover (Gibson et al. 2002; Potter 2003; Solomon 2000). This is largely due to the fact that they offer employees the flexibility to attend to personal needs during the work day as need be and then complete work "on their own time." Telework can be a significant factor influencing the retention of talent as telework options can eliminate the need for an employee to relocate with a transferred partner/spouse as noted above. It can also facilitate the earlier re-entry to work of an employee on any kind of Family and Medical Act-related leave, such as for the birth or adoption or a child or for the serious illness of the employee or an immediate family member.

A sixth and more newly-documented and realized benefit of telework programs is that they provide resilience to employers when faced with unexpected circumstances or events that might interrupt business operations, such as a transport strike, severe weather, act of nature or natural disaster. For a number of years AT\&T realized many of the more traditional benefits associated with telework, such as reduced real estate costs, productivity gains and enhanced employee satisfaction and retention. However, in the aftermath of Hurricane Katrina in 2005, AT\&T witnessed another benefit of telework; business continuity, which was provided when a majority of employee home-based work sites were unaffected by the hurricane (Roitz and Jackson 2006). A further example of resilience is seen when considering the New York City transit strike of December 2005. Estimates of the cost of the strike to the city's economy are roughly $\$ 1$ billion (Bailor 2006). However, these estimates found that the costs would have been higher had employers not had telework capabilities in place, allowing knowledge workers to work from home and remain productive throughout the strike (Bailor 2006).

Related to the benefit of resilience, a seventh employer benefit of telework programs is that they can provide geographical dispersion that can reduce vulnerability in the case of a terrorist attack (Potter 2003). The September 11, 2001 terrorist attacks were a watershed event for telework as employers tried to "decentralize intellectual property" as well as accommodate workers who became fearful of working in skyscrapers and crowded cities and taking mass transit to work in large cities. Immediately after the attacks Freddie Mac, a DC-based nationwide buyer of home mortgages, directed its managers to immediately implement a large scale telework process that was being considered but still under discussion (Joyce 2001).

From a public health perspective, a major component of the current Bush administration plan to defend against any kind of national or global influenza epidemic is to rely more 
heavily on telework. Toward this end, a recent White House Report recommends that employers develop a plan that plans for and accommodates " $40 \%$ of their staff for a period of about 2 weeks with fewer employees absent for a few weeks on either side of the peak" (Hoffmann 2006).

An eighth and well-documented benefit for employers of telework is that it can provide increased recruitment options and expansion of the available labor pool. As previously discussed telework can allow employers to recruit, consider and employ individuals who are not available to work at the employer's place of employment, such as those with family obligations and various disabilities that prevent or restrict travel. Telework programs have become a key strategy in the retention of in-demand information technology workers (McGee 2005). Telework is also a major perk desired by many younger workers (Kennedy 2005). It is also seen as a means of allowing individuals in older age groups to maintain employment when commuting to the office becomes too difficult (Ruiz and Wailing 2005).

\section{Employee Benefits}

In addition to the benefits employers can realize from telework programs, employees who telework also experience numerous benefits, which has fueled the demand for and desirability of telework options among employees. These benefits are explained below.

The first benefit employees who engage in telework receive is increased job satisfaction (Manochehri and Pinkerton 2003; Tremblay 2002). Employees who engage in telework often feel less pressure to produce and give the appearance that they are "busy," allowing them to enjoy their work more than when it is performed in an office environment. This increased job satisfaction is also a by-product of having more control over the balance of work-family life (Crandall and Gao 2005). In addition the flexibility of working at times they chose can enhance satisfaction in that lifestyles can be better accommodated and employees can work in tandem with their own daily "rhythms" or body clocks. The reduction of stress that results from disruption of family life can also increase job satisfaction.

A second benefit to employees who engage in telework is the savings in time and money that result from the reduction of travel time and expenses. A typical employee who engages in telework can save approximately $1 \mathrm{~h}$ each day on commuting time (Potter 2003). In addition employees save on automobile and gasoline expenses as well as on out-of-pocket wardrobe and associated dry cleaning expenses.

A third benefit is that most employees who engage in telework have increased productivity (Crandall and Gao 2005), some of which may be attributable to their increased job satisfaction. Employees who work away from the employer's work site generally experience fewer distractions that can hinder completion of assignments which can be particularly beneficial for tasks, assignments or projects which require extended periods of concentration. Productivity gains can also be attributed to less exposure to and involvement with office politics (Manochehri and Pinkerton 2003; Robertson et al. 2003) and the resultant effects politics can have on behavior and performance. Increased productivity can result in enhanced career opportunities within the organization.

A final benefit to employees provided by telework is that it provides otherwiseunavailable opportunities afforded to employ home-bound individuals (Baruch 2000), such as new parents and other caregivers, the elderly, those with disabilities and those residing in rural areas. When available job opportunities are not restricted to those applicants who live 
within a reasonable commuting distance, individuals who might otherwise remain unemployed are afforded the opportunity to contribute to the economy and earn a living.

\section{Potential Limitations of Telework}

Despite the numerous benefits that telework programs provide to employers, employees and the larger society, as summarized in Table 1, some employers have actually implemented telework programs but subsequently reverted back to office-based work after the experience of telework. The reason for this is the fact that there are some potential shortcomings or limitations of a telework program that is not conceptualized, implemented and managed appropriately. These potential problems can be experienced by both the individual employee and the organization itself and are explained below and summarized in Table 2.

\section{Employees}

There are three major issues concerning employees that must be addressed in order to ensure that a telework program provides benefits that exceed its costs. The first of these is that telework programs can result in employees experiencing isolation from the company culture (Crandall and Gao 2005). Not being physically present removes a significant component of employee/co-worker/supervisor interaction. Some employees have misgivings about the loss of such social interaction as well as an associated fear that career advancement may be stalled by the off-site employee being both "out of work" and "out of mind" (Baruch 2001; Gibson et al. 2002). It has been noted that telework greatly alters the dynamics of office politics, for better or worse (Kennedy 2005) in addition to altering the social, physical and psychological contexts of work. Because telework removes direct

Table 1 Benefits of telework.

\section{Environmental}

Reduced traffic and pollution

Reduced strain on public transport systems

\section{Employer}

Increased productivity

Improved morale and motivation

Enhanced customer/client service

Reduced operating costs

Retention aid

Reduced absenteeism and turnover

Resilience

Geographic dispersion

Increased recruitment options

\section{Societal}

Assist in the employment of those with disabilities, the elderly, new parents, others who may not be physically able to get to work

\section{Employee}

Increased job satisfaction

Savings in personal expenses/time Increased productivity

Enhanced employment opportunities 
Table 2 Potential limitations of telework.

\begin{tabular}{ll} 
Employees & Employer \\
\hline Potential isolation & Measuring performance \\
Anxiety over "visibility" & Impact on teamwork \\
Potential for work/family conflict & Safety and liability \\
& Sufficiency of technology \\
& Security of information \\
& Selection of eligible employees \\
& Provision of telecommunications hardware \\
& Supervisor discomfort
\end{tabular}

Employees

Potential isolation

Anxiety over "visibility"

Potential for work/family conflict

\author{
Employer \\ Measuring performance \\ Impact on teamwork \\ Safety and liability \\ Sufficiency of technology \\ Security of information \\ Provision of telecommunications hardware \\ Supervisor discomfort
}

supervision and alters coordination, communication and feedback, organization-related identification and verification can become more ambiguous for employees. (Thatcher and Zhu 2006).

A second issue regarding telework from the employee perspective is potential anxiety about being passed up for promotions and missing out on "good projects" (Crandall and Gao 2005; Khalifa and Davidson 2000). For some employees, telework has been shown to result in feelings of isolation, uncertainty over the employee's relationship with those at the physical work site and frustration over potential doubts of co-workers over the employee's credibility as a serious employee (Baruch 2000; Baruch and Nicholson 1997; Scott and Timmerman 1999). The resultant stress might offset any potential gains in productivity the employer realizes as well as cause the employee to feel insecure about her or his "place" and security in the organization, having a detrimental impact on retention.

A third employee-related issue is, despite the fact that telework can generally allow an employee to better manage the work-family interface, unless the employee is very welldisciplined, the potential exists for work/family conflict and at-home distractions when an employee engages in telework. Problems associated with maintenance of the boundaries between home and work can be difficult for some employees, causing enhanced stress and even burnout. In addition, supervisors need to remember that an employee who is based off-site is not necessarily available around the clock and to respect boundaries. Previous research on work_family conflict that results from telework has suggested that employees who telework develop specific boundaries, where they restrict access to home-based work space by family members, as well as engage in rites of passage, where they actually "dress for work" and/or take breaks at specified times, as well as actually replicate the temporal and physical sensations one experiences at the employer's work site (Ahrentzen 1990; Edwards and Rothbard 1999). However, not all employees engage in this behavior nor do employers realize the need to encourage it.

\section{Organization}

While employers can reap many significant benefits from telework programs, there are some important issues that need to be addressed to ensure success of any such program. The first of these is devising a way to measure performance. This is an overwhelming concern of many managers who oversee employees who engage in telework (Crandall and Gao 2005). Managers may have reservations over whether employees are actually being as productive away from the office as they would be if physically present, may feel powerless 
in providing employees with more meaningful feedback (Manochehri and Pinkerton 2003) and also struggle with performance appraisals and assessments without a greater presence of the employee in the workplace (Crandall and Gao 2005).

A second employer-issue related to telework is its impact on the development of a strong sense of teamwork within the work group that is increasingly important in organizations (Baruch 2001; Gibson et al. 2002; Mills et al. 2001). Much of this concern is anecdotal at this point as no published empirical research, as of yet, has focused on how virtual work might alter work relationships and affect important work outcomes (Golden 2006). Ironically, telework has been seen as somewhat of a paradox by some in that its flexibility allows employee and employer demands to be met simultaneously but it also fragments collectivity and produces exclusion (Taskin and Devos 2005).

A third employer concern is employee safety and any resultant liability for injury that may occur at the employee's home or any off-site work location. On February 25, 2000 the United States Occupational Safety and Hazard Administration issued policy guidelines on employee "home offices." These guidelines provided that OSHA would not conduct any kind of inspections of employee home offices nor would it hold employers liable for the safety of nor require employers to inspect employee home offices. However, the guidelines reiterated OSHA's position regarding employer responsibility for documentation of any work-related injuries or illnesses, regardless of where they occur. In addition, because many state worker compensation laws do not distinguish between employer offices and employee home-based offices, it is critical for employers to document whether an injury that occurred at the employee's home was work-related, took place at the home-based worksite and happened within the course of actually completing the employee's work-related responsibilities as fraudulent worker's compensation claims can increase the employer's costs of doing business.

A fourth employer-related issue is ensuring that the organization's technology and servers have adequate capacity to support the telework program (Harpaz 2002). Remote access to networks and data is critical to ensuring and maintaining productivity and telework employees can not have technical specialists "troubleshoot" problems as readily when they are at home or working remotely than when they are physically on-site.

A fifth employer-related issue is ensuring the security of sensitive work information that is being accessed and worked on in employee's homes and/or transported by employees offsite on laptop computers or data storage devices (Leonard 2001). While many issues of security breaches regarding sensitive information have been reported, none gathered as much attention as that which took place in May 2006 when the US public was informed that the social security numbers and other personal information from 26.5 million retired and active US military personnel were contained on a laptop computer stolen from the home of a Department of Veterans Affairs employee (Joyce 2006). Indeed, a critical issue that needs to be addressed in any telework program is access to information, particularly information contained on computers that will be taken from the office and/or files that will be accessed from home and how security of that information can be maintained (Crandall and Gao 2005). If employees work with company data from computers at home security can be maintained through a Virtual Private Network (VPN) line along with multiple firewalls and complicated log-in procedures (Joyce 2006). In addition, employees' "work-at-home" computer should be dedicated to work use only to ensure security (Messmer 2006).

Another employer-related issue that needs to be addressed in a telework program is the selection of eligible employees. In order to fully realize the benefits of telework, an employer needs to ensure that employees who engage in telework be self-disciplined and 
motivated to allow them to appropriately manage the potential numerous distractions that may present themselves at home. A given employee's home may not lend itself to telework due to problems with space, technology, security, and family/lifestyle issues. More so, not all tasks can be performed as effectively away from the office.

A seventh-employer related issue concerns the costs of ensuring that an employee who engages in telework has the appropriate hardware, software, and telecommunications modes to be as productive off-site as at the office. This can be a significant expense and the employer has to consider how much of the costs are to be employer-assumed and/or subsidized.

Finally, employers need to consider supervisor discomfort that may exist regarding subordinate telework. As previously mentioned, supervisors often feel that they have less control over employee behavior and productivity when employees are off-site. In addition, supervisor issues concerning telework often go beyond employee accessibility and productivity and extend to concerns that the supervisor's jobs may become obsolete if employees can perform at sufficient levels of performance without direct "live" supervision. As an increasing number of organizations reduce layers of management, this perception on the part of managers may be very real indeed. However, at the same time, even when subordinates are on-site, very few managers ever get a "live" response at work. More commonly an employee may respond by voice or e-mail rather than an in-person meeting. Hence, the mandate for "constant accessibility" by managers is hardly realistic or necessary. Nonetheless supervisor discomfort/resistance is probably the main reason fewer employees engage in telework.

\section{Recommendations/Keys to Successful Telework Programs}

The above discussion illustrates that telework programs can provide significant benefits yet, at the same time, need to be implemented carefully to avoid a number of potential problems that could result in the benefits of telework being severely undermined. In addition to some of the recommendations listed within the earlier discussion, several others can be provided that can assist in developing an effective telework program, as outlined in Table 3.

First, the job responsibilities for the position that is being considered for telework must be suited to performance off-site. Responsibilities that require a good deal of clarification, communication and information-sharing that involves interpretation necessitate a good deal of back-and-forth exchange that may be accomplished more effectively through "live"

Table 3 Recommendations.

Ensure that job responsibilities can be performed off-site

Ensure that employees can work with minimal supervision/direct contact

Ensure that telework program has broad institutional support

Ensure that supervisors understand and believe in the value of telework

Ensure that off-site workspaces are distraction-free, safe and secure 
discussion and meeting than through telecommunication. Job responsibilities that involve independent work and/or work that requires a good deal of concentration without interruption may be well-suited for telework.

Second, any employee who is afforded the option to engage in telework must be able to work with little or no direct supervision and with minimal face-to-face contact with coworkers. Some employees need and/or desire a good deal of interaction with co-workers and a more social work environment whereas others prefer to work in greater social isolation. Similarly, some employees need and/or desire regular or continuous reinforcement from supervisors about their work where as other employees are more self-motivated and/or satisfied by self-generated feedback from the work itself. Some lost interaction can be replaced by virtual rooms called the "watercooler" where employees can post comic strips and jokes, and comment on everything from the employee picnic to baseball games and particular television shows (McAdams 2006).

Third, in order for a telework program to succeed, the employer and managers of employees who engage in telework must accept telework as a legitimate, beneficial and desirable activity and support it via appropriate information technology. Telework requires financial investment in networking systems and also requires that the organization view telework as an important strategic aspect of job/work design and employees throughout the organization understand its legitimacy rather than perceive it as an option for co-workers to "slack off".

Fourth, supervisors of employees who engage in telework must see and believe in the benefits provided by telework. The most common reason for failure of telework programs is managerial resistance due to the perception that employees need to be directly supervised to ensure that they remain busy. Managers with subordinates who engage in telework tend to spend an inordinate amount of time checking on what employees are actually doing at home rather than checking on the work being done (Piskurich 1998). Focus needs to be placed on the quality and timeliness of work being produced rather than hours worked or time on each task. Telework programs can be aided by a system that allows employees to report periodic progress on tasks and receive appropriate feedback. The reality of telework though is that supervision of off-site employees is actually no different that supervision of on-site employees. Ideally, direct supervisors assign work and hold subordinates accountable for agreed-upon, measurable results.

One of the most effective means of addressing supervisor resistance to offer telework to employees is the development and implementation of a comprehensive performance management system. Employers who have already-established performance management and feedback systems that focus on goal-setting and/or objectives-based performance have found that such a system greatly facilitates the introduction of a telework program. In most cases, little to no modification is needed to ensure that any employee who works off-site has a clearly defined set of measurable performance objectives which can be monitored and assessed via timely feedback. These objectives can be incorporated into any formal telework program and provide supervisors with the incentive to at least allow employees to work off-site on a piloted or trial basis.

Finally, employees must have suitable workspace at home, free from distractions and with appropriate safety and security measures. A suitable workspace would be one that is ergonomically "correct" to prevent any kind of repetitive motion and/or ocular injuries, that has adequate telecommunication capabilities to ensure sufficient virtual "presence" at work throughout the agreed-upon work hours and that is sufficiently separated from the employee's living space and possible distractions to allow the employee to focus on her or his work. 


\section{Summary}

Telework is seen as a management practice that provides myriad benefits to both employees and employers as well as the larger society. The importance of telework to our society and economy is reflected in the fact that Congress has established a nonprofit organization, the Telework Consortium, based in Herndon, VA, to address telework issues as diverse as continuity of operations, traffic patters and work/life balance (McAdams 2006).

Telework involves a stark contrast to traditional means of on-site employment. It is a means of designing jobs that requires a different mindset and perspective from both employers and employees. It should not be surprising that employers who utilize telework options for employees also utilize different management practices from those employers who do not utilize telework. Among the notable differences between telework employers and nontelework employers is that telework employers have a higher investment in R\&D, greater percentages of knowledge workers and salespeople, larger geographical market, more employee training and more employee participation in job design and work planning. Relative to HR, telework employers utilize more flexible HR systems, variable compensation, outsource non-essential functions more frequently and emphasize objectives-based performance management systems (Perez and Sanchez 2005). Many of the employers who engage in and promote telework see it as providing them with a competitive advantage not only in the recruiting and retention of employees but also in increasing efficiency of operations and workforce productivity.

Telework options and the means of and capabilities afforded by telework will continue to evolve as will the abilities of employees who engage in telework to be more fully part of the organization which employs them. Continued advances in information processing and technology expand the markets and opportunities present for virtually all employers as well as fundamentally change the ways in which organizations operate. Additional changes in societal and labor force demographics and lifestyles continue to challenge employers relative to the recruitment and retention of the best employees. Newer generations entering the work force have different needs and attitudes toward work than those of past generations. Advances in medical technology and treatment that afford individuals the opportunity to remain healthy and working far later in their lives than in the past create additional challenges for employers. One common theme among and across generations and demographics, however, is the desire for greater flexibility in job assignments and work arrangements. Increasing concerns related to environmental impact and sustainability continue to fuel the call for creative solutions to alleviate the detrimental impact of automobile use and commuting on our society and world.

Telework is a potential solution to many of these societal and organizational concerns. The continuing growth in both its popularity and desirability is inevitable as an increasing number of incentives are provided for new employer-sponsored telework programs and additional successful telework programs are developed, implemented and publicized. However, telework is not a guaranteed solution to all of the issues that it can potentially address. Telework programs that are not planned, designed and implemented with a full understanding of some of the potential issues and limitations that surround its use can result in more cost than benefit to employers. Those implemented from a more macro/strategic perspective that are designed and developed with an eye towards and fully integrated into the organization's overall strategic plan and culture can not only provide employers with a competitive advantage in attracting and retaining employees, enhancing productivity and lowering operating expenses but also allow the employer to display its social responsibility. Telework is clearly here to stay and employers can ill afford not to consider telework 
options for employees if they are to remain competitive. This paper has shown that the potential obstacles to developing and implementing a successful telework program can be anticipated and planned for as part of an overall strategic approach to managing both employee performance and overall organizational performance.

\section{References}

Ahrentzen, S. B. (1990). Managing conflict by managing boundaries: How professional home workers cope with multiple roles at home. Environment and Behavior, 22, 723-752.

Arnold, J. T. (2006). Making the leap. HR Magazine, 51(5), 80-86.

Bailor, C. (2006). NYC rides with telecommuting. Customer Relationship Management, 10(3) 11-12.

Bangemann, M. (1994). Europe and the global information society. Brussels: European Commission.

Baruch, Y. (2000). Teleworking: Benefits and pitfalls as perceived by professionals and managers. New Technology, Work and Employment, 15, 34-49.

Baruch, Y. (2001). The status of research on teleworking and an agenda for future research. International Journal of Management Reviews, 3(2), 113-129.

Baruch, Y., Nicholson, N. (1997). Home, sweet work: Requirements for effective home working. Journal of General Management, 23(2), 15-30.

Bednarz, M. (2005). Teleworking takes off in Atlanta. Network World, 22(38), 45, Sept 26, 2005.

Crandall, W., \& Gao, L. (2005). An update on telecommuting: Review and prospects for emerging issues. $S$. A.M. Advanced Management Journal, 70(3), 30-37.

Edwards, J. R., \& Rothbard, N. P. (1999). Work-family stress and wellbeing: An examination of personenvironment fit in the work and family domains. Organizational Behavior and Human Decision Processes, 77, 85-129.

Garner, G., \& Dick, G. (2007). Telecommuting: A managerial perspective. retrieved from http://sistm.web. unsw.edu.au/people/gndick/garner.pdf (on February 8, 2007).

Gibson, J., Blackwell, C., Dominics, P., \& Demerath, N. (2002). Telecommuting in the 21st century: Benefits, issues, and a leadership model which will work. Journal of Leadership and Organizational Studies, 8(4), 75-86.

Golden, T. O. (2006). The role of relationships in understanding telecommuter satisfaction. Journal of Organizational Behavior, 27(3), 319-364.

Harpaz, I. (2002). Advantages and disadvantages of telecommuting for the individual, organization and society. Work Study, 51(2/3), 74-80.

Hoffmann, M. A. (2006). Government release pandemic plan. Business Insurance, 40(19), 3-4, May 8, 2006.

Joyce, A. (2001). Getting in gear to telecommute. Washington Post, E-1, 10, December 31, 2001.

Joyce, A. (2006). Lost laptops a wake-up call for telecommuters. South Florida Sun-Sentinel, June 19, 2006, BR-13.

Kennedy, M. M. (2005). Consider office environment before offering telecommuting. Marketing News, 39(17), 54-55, Oct 15, 2005.

Khalifa, M., \& Davidson, R. (2000). Exploring the telecommuting paradox. Communications of the ACM, 42(3), 29-30.

Kirk, J., \& Belovics, R. (2006). Making e-working work. Journal of Employment Counseling, 43(1), 39-46.

Kossek, E. E., Lautsch, B. A., \& Eaton, S. C. (2006). Telecommuting, control and boundary management: Correlates of policy use and practice, job control and work-family effectiveness. Journal of Vocational Behavior, 68(2), 347-367.

Kurland, N. B., \& Bailey, D. E. (1999). Telework: The advantages and challenges of working here, there, anywhere and anytime. Organizational Dynamics, 28(2), 53-67.

Leonard, B. (2001). Few employees are embracing telecommuting. HR Magazine, 46(3), 31.

Manochehri, G., \& Pinkerton, T. (2003). Managing telecommuters: Opportunities and challenges. American Business Review, 27(1), 9-16.

McAdams, J. (2006). Telecommuters. Computer World, 40(20), 36-37, May 15, 2006.

McGee, M. K. (2005). Retention tension. InformationWeek, Nov 7, 2005 Iss 1063, 49-51.

Messmer, E. (2006). Telecommuting security concerns grow. Network World, 23(41) 43, April 24, 2006.

Mills, J., Wong-Ellison, C. Werner, W., Clay, J. (2001). Employer liability for telecommuting employees. Cornell Hotel and Restaurant Quarterly, 42(5), 48-59.

Nie, N. (1999). Tracking the techno future. American Demographics, July, 50. 
Perez, M., \& Sanchez, A. M. (2005). The differences of firm resources and the adoption of teleworking. Technovation, 25(12), 1476-1483.

Piskurich, G. (1998). An organizational guide to telecommuting. Alexandria, VA: American Society for Training and Development.

Potter, E. (2003). Telecommuting: The future of work, corporate culture and American society. Journal of Labor Research, 24(1), 73-84.

Robertson, M., Maynard, W., \& McDevitt, J. (2003). Telecommuting: managing the safety of workers in home office environments. Professional Safety, 48(4), 30-36.

Rockridge Associates, Inc. (2006). 2005/2006 National technology Readiness Survey. July 12, 2006. Retrieved from http://www.management-issues.com/display_page.asp?section=research\&id=3403 (on August 8, 2006).

Roitz, J., Jackson, E. (2006). Alternative work arrangement: AT\&T adds business continuity to the long list of telework's advantages. Journal of Organizational Excellence, 25(2), 3-12, Spring 2006.

Ruiz, Y., \& Walling, A. (2005). Home-based working using communication technologies. Labour Market Trends, 113(10), 417-426.

Scott, R. C., \& Timmerman, C. E. (1999). Communication technology use and multiple workplace identifications among organizational teleworkers with varied degree of virtuality. IEEE Transaction on Professional Communication, 42(4), 240-260.

Solomon, C. (2000). Don't forget your telecommuters. Workforce, 79(5), 56-63.

Stallion Technologies (2002). The history and direction of telecommuting. retrieved from http://www. stallion.com.au.html.solutions/telecommuting-directions.html (on February 8, 2007).

Taskin, L., \& Devos, V. (2005). Paradoxes from the individualization of human resource management: The case of telework. Journal of Business Ethics, 62(1), 13-24.

Thatcher, S. M. B., \& Zhu, X. (2006). Changing identities in a changing workplace: Identification, identity enactment, self-verification, and telecommuting. Academy of Management Review, 31(4), 1075-1088.

Thibodeau, P. (2006). Hotel chain takes new tack on call center IT. Computerworld, 40(3), 8, Jan 16, 2006.

Tremblay, D. G. (2002). Balancing work and family with telework? Organizational issues and challenges for women and managers. Women in Management Review, 17(3/4), 157-170.

United States Bureau of Transportation Services (2006). Transportation Implications of Telecommuting. National Transportation Library, a program of the Bureau of Transportation Services; retrieved from http://ntl.bts.gov/DOCS/telecommute.html (on August 7, 2006).

Vidal, S. (2004). Australia Telecommuting Services and Equipment 2004-2008 Forecast and Analysis. ICD Australia. retrieved from http://www.idc.com.au/research/document.asp?document_id=235 (on February $8,2007)$. 